\title{
Influence of Students' Entrepreneurial Psychological Capital on Entrepreneurial Exploratory Learning under the Background of Extended Reality (XR)
}

\author{
https://doi.org/10.3991/ijet.v17i01.28537 \\ Zhe Liu \\ College of Culture and education, Henan Economy and Trade Vocational College, Zhengzhou, \\ China \\ liuzhe2020@henetc.edu.cn
}

\begin{abstract}
Students can carry out exploratory learning of entrepreneurial knowledge by reducing costs and improving efficiency. At the same time, this technology can bring new immersive experience to students and provide them with the opportunity to become the designer and creator of entrepreneurial knowledge. Based on the theory of emotion and social cognition, this study puts forward the research model of students' entrepreneurial psychological capital on entrepreneurial exploratory learning. XR technology also tests whether students' entrepreneurial psychological capital plays an intermediary role in promoting entrepreneurial exploratory learning. The results show that Cronbach $\alpha$ The coefficient is 0.844 , the kmo value is 0.787 , and the significance is 0.000 , indicating that the designed questionnaire has good reliability and validity. XR technology plays a complete intermediary role in the positive promotion of students' entrepreneurial psychological capital society to students' entrepreneurial exploratory learning. This study is of great significance for understanding the important value of XR technology in exploratory learning, enriching the application research of psychological capital in the field of entrepreneurship, and innovating the teaching mode of students' Entrepreneurship Education from the perspective of psychological capital.
\end{abstract}

Keywords-extended reality (XR), students' entrepreneurial psychological capital, entrepreneurial exploratory learning

\section{Introduction}

China, as a large educational country, is actively promoting the in-depth integration and large-scale application of the extended reality (XR) technology industry in the field of education. In particular, China's XR technology has been relatively mature, with large market scale and obvious user activity. At the same time, all provinces in China have noticed the importance of the XR technology industry to economic development, social progress and educational soft power enhancement. They have also issued many documents to support the development of virtual reality (VR) industry [3]. XR technol- 
ogy, as an important representative of emerging technology industries, covers augmented reality (AR), VR, and hybrid reality. After integrating these technologies, XR technology has more market core competitiveness and application space. Among them, AR technology displays in real time by virtualizing real scenes, and VR enables users to truly simulate various behaviors and operations in the real world in virtual scenes. Especially, with the development of artificial intelligence (AI) industry, AR, VR, mixed reality (MR), and other technologies can be fully integrated. This way creates all-round, multi-angle, and immersive experience scenes and divisions needed in the education process, and it provides potential space for the reform of education and teaching methods. XR technology reduces the subjective dependence on the subject of education evaluation by centralizing all the data of the educational process characterized by high complexity, multiple nonlinearity, and sea quantification of data in the field of education. It uses big data, $5 \mathrm{G}$, and AI to realize timely feedback to the subject and object of the educational process, and it improves the teaching and final education effects. Therefore, the development of XR technology is providing a solid support for learners to step into the vast practical learning space without leaving home.

With the wide popularization of XR technology, students' entrepreneurship education is also facing opportunities and challenges. In particular, the number of Chinese students is huge, and entrepreneurship has also become a channel to understand the employment of students. However, at present, entrepreneurship education for Chinese students still stays in textbooks, does not pay sufficient attention to students' entrepreneurial psychological capital, and does not incorporate XR technology into entrepreneurship courses. A large number of studies have shown that students' entrepreneurial psychological capital covers a wide range, including factors such as self-efficacy, optimism, and positivity. Students can more easily accept more advanced education methods when the entrepreneurial psychological capital is stronger. Thus, they can maintain a positive attitude and an optimistic attitude toward the entrepreneurial prospects in the highly uncertain and fully risky entrepreneurial process. XR technology, as a novel means of education and teaching, has been popularized and applied in social life. XR technology has entered every field of life with the rapid development of China's digital industry. Under the background of increasingly becoming lower cost of XR technology, the cross-integration of XR technology with AI, Internet of Things, and mobile information technology has lowered the technical threshold of XR educational resources, which can enable students to conduct exploratory learning of entrepreneurial knowledge with higher quality. XR expands the application of reality in teaching. Thus, entrepreneurial knowledge learning with more nonlinear characteristics will gradually become the norm. XR technology can make students change from the role of educate in the traditional classroom to the active participant and experiencer in the entrepreneurial process. This way makes students' psychological capital play a better role, and it promotes students to carry out more extensive entrepreneurial exploratory learning. Therefore, this study develops an entrepreneurial psychological capital questionnaire, combined with the classic questionnaire, based on XR technology to verify and measure the structure of entrepreneurial psychological capital. The relationship between students' psychological capital and entrepreneurial exploratory learning can also be validated. 


\section{Theoretical basis and hypothesis presentation}

\subsection{Theoretical basis}

Lazarus, R.S. shared his views in the cognitive theory of emotion. He thinks that emotions are produced by external evaluation of the environment, and a close relationship exists between self-emotion and knowledge of things [1]. He found that personal physiology, surrounding environment, and cognitive process can all affect the generation and change in emotions, especially cognitive process is the main reason that affects emotions. In the process of generating people's emotions, people are not simply passively accepting the stimulation influence of surrounding things on individuals, and individuals also actively adjust their response to stimulation. Under the guidance of cognition, this process makes individuals fully understand the relationship between surrounding things, evaluate the beneficial and harmful factors in the environment, promote individuals to choose more appropriate and valuable action responses, and realize the full integration of individuals and the surrounding environment.

American psychologist Bandura, A put forward a ternary interaction mechanism in the theory of social cognition [2], that is, a relatively close interaction exists among individual factors, surrounding environment, and individual behavior, and the three factors are mutually located but interact with one another. Among them, the interaction between individual and environment makes individual behavior subject to the demonstration and influence of external environment, such as economy, culture, and system. Conversely, individual factors will also affect people's experience of the environment and their cognition of the environment to a certain extent.

\subsection{Research hypothesis}

Luthans (2004) emphasized that psychological capital consists of four dimensions: hope and optimism, self-efficacy, enthusiasm and innovation [3], and social wisdom. Hope means that individuals can stick to their goals and choose new ways to achieve them when necessary. Self-efficacy means that an individual has strong confidence in his ability to recognize resources, stimulate motivation, take action, and finally achieve success when he performs a task under certain circumstances. Enthusiastic innovation means that individuals can make positive attribution to current and future successes and failures, and they can be more enthusiastic to create some new solutions to problems. Social intelligence refers to individuals participating in social activities, interacting with others, choosing appropriate behaviors in various situations of different environments and objects, maintaining a good attitude and communication skills, and promoting the successful completion of things.

Ahene-Gima, $\mathrm{K}$ believed that exploratory learning can improve students' income in the future and effectively stimulate their learning activities to develop new business in the market, develop new skills needed in the process of work, and acquire these new technical skills [4]. Given that entrepreneurship is difficult for students, entrepreneurial exploratory learning refers to that students improve their entrepreneurial performance through continuous entrepreneurial test process, explore new technologies suitable for 
market development needs, and obtain innovative products or services different from existing standards and management rules.

With regard to self-efficacy and exploratory learning, Power, $\mathrm{J}$ argued that touching self-efficacy is the key to improving participation and performance in the learning process. Students' self-efficacy and related positive results should be comprehensively improved. Shen, D believed that self-efficacy is the key factor of successful online learning [6]. The research results showed that students' self-efficacy in online learning process predicts students' online learning satisfaction. Choi, $\mathrm{N}$ used bandura multidimensional self-efficacy scale (MSPSE) to measure freshmen's self-efficacy [7]. The research showed that bandura multidimensional self-efficacy scale has a very good application prospect and good reliability and validity. Ruys, I (2010) conducted a detailed survey on self-efficacy of 489 teachers and student teachers [8]. The results showed that students' self-efficacy can effectively promote students to strengthen cooperative learning with teachers. Greiman, B. C introduced youth leadership development selfefficacy (yld-se) as a new structure of leadership research [9]. The results showed that transformational and laissez faire leadership styles are important predictors of success. Chiaburu, D. S showed through an experimental study that self-efficacy can provide the overall skill level of trainees [10]. Zheng, J investigated students' technical acceptance, motivation, and self-efficacy in e-school learning [11]. The research showed that differences exist in self-efficacy among different groups of students, and the selfefficacy is stronger when the score is higher. In summary, self-efficacy means having self-belief, being able to cope with challenges freely, and being able to handle multiple tasks at the same time, which can make students choose to accept exploratory learning when starting a business. Self-efficacy can promote students' learning effect in exploratory learning, encourage them to cope with difficulties on the road of entrepreneurship, and increase the success rate of entrepreneurship. Therefore, this study puts forward the following hypothesis:

H1: Students' self-efficacy can positively promote students' entrepreneurial exploratory learning.

With regard to hopeful optimism and exploratory learning, Stankevicius, A argued that optimists hold positive beliefs about the future, which can directly affect learners' learning process [12]. Hoy, W.K. analyzed the relationship between academic optimism and students' achievement, and the results showed that academic optimism significantly contributes to students' achievement [13].

Kulophas, D conducted a questionnaire survey on teachers and principals of 159 middle schools in Thailand [14]. The research showed that academic optimism is the intermediary role of school leaders in supporting teachers' professional learning. Hamm, J.M. found that optimistic and hopeful students are more likely to accept academic innovation activities [15]. Di Paolantoni, $M$ analyzed the definition of optimism in education and believed that optimistic learners are more accustomed to the cultivation of learning behavior [16]. Rose, E analyzed students' preference for online courses and their use habits of learning management system [17]. The research showed that students who hope to be optimistic pay more attention to accepting online courses. Overall, if students have a more optimistic and hopeful attitude, then they can face the risks and adjustments of the entrepreneurial process. At the same time, they have a 
higher entrepreneurial possibility by exploratory learning of the entrepreneurial process and entrepreneurial knowledge. Therefore, this study puts forward the following hypothesis:

H2: Optimism of students' hope can positively promote students' entrepreneurial exploratory learning.

For enthusiastic innovation and exploratory learning, Slick, S showed that teachers are the main body of imparting knowledge [18], and their enthusiastic participation is one of the main reasons for improving the learning effect of learners in the learning community. Derobertis, E.M. adopted a qualitative research method to study how students first experienced enthusiasm for the learning process in childhood. The results showed that students' enthusiasm for learning can keep their motivation and improve their learning effect [19]. Serin, $H$ found that passion is an important demand for highquality learning and teaching. Passion promotes learning, stimulates thorough desire and enthusiasm, and can improve students' learning potential [20]. Noble, K. D argued that courses for young students need to fully stimulate their learning enthusiasm in the first year [21]. Horng, J. S conducted a questionnaire survey on the results of entrepreneurship education among 446 students majoring in tourism and hotels [22]. The results revealed the intermediary role of entrepreneurship content, learning enthusiasm, and entrepreneurship Promotion between knowledge application and entrepreneurial tendency. Kutnowski, M found that students' learning enthusiasm is very important in music courses and art design courses [23]. Wang, Y. F argued that students' learning enthusiasm can significantly promote the initiative of curriculum learning. In summary, students who are enthusiastic and innovative are more courageous to take responsibility [24]. They are more likely to produce solutions when faced with the uncertainty of new things and entrepreneurial process. They are also encouraged to accept the exploratory learning method of entrepreneurship, which further promotes their enthusiasm and innovation ability, meets their internal needs for entrepreneurship, and enables them to have higher entrepreneurial intentions. Therefore, this study puts forward the following hypothesis:

H3: Students' enthusiasm and innovation can positively promote students' entrepreneurial exploratory learning.

With regard to social intelligence and exploratory learning, Suliman, W.A. discussed the differences in social intelligence between traditional and accelerated courses for Saudi nursing students [25]. The results showed that social intelligence helps students choose online courses more, and the learning effect is more obvious. Kaukiainen, A found a positive correlation between social intelligence and learning skills [26]. Arghode, V revealed that social intelligence plays a role in teaching [27]. If students get more support and encouragement from teachers, then students will feel connected with teachers, which will further improve their learning achievements. Seal, C. R believed that the learning process can improve the ability of social intelligence [28]. After the improvement in social intelligence, it can further guide learners to strengthen curriculum design and implementation and promote the improvement in learning effect. Kong, $\mathrm{E}$ argued that social intelligence represents the tacit knowledge, ability, and skills of organization members [29]. Social intelligence has a dynamic impact on enterprise human capital development and organizational innovation learning. Meyer, K. A found 
that students with stronger social intelligence are more likely to accept online learning methods [30], and social intelligence is easier to be reflected in online curriculum. Overall, students are more likely to choose challenging exploratory learning methods when their social wisdom is stronger. They can also more confidently interact with other people in the society (e.g., enterprise tutors and graduates who have successfully started businesses). They can learn the experiences of successful social entrepreneurs as well, which will be transformed into knowledge gains in the process of self-exploratory learning. Thus, the possibility of their success in starting businesses will be improved. Therefore, this study puts forward the following hypothesis:

H4: Students' social intelligence can positively promote students' entrepreneurial exploratory learning.

Kang, J showed that using real-time simulation and embedded simulation can obviously promote learners' learning experience [31]. Nisiotis, L mentioned that using XR, $\mathrm{AI}$, and robotics can fully support the educational network physical social ecosystem of immersion learning and can improve the learning effect [32]. Ioannou, A thought that XR technology can improve the immersive and experiential learning environment and improve the current learning process [33]. Young, A believed that the effective use of XR in the learning environment can promote the cooperation between teachers and students and jointly create AR and VR experiences [34]. Thus, STEM literacy rate can be improved. Therefore, XR technology can completely produce an immersive entrepreneurial exploratory learning environment, which greatly meets the needs of students' entrepreneurial experience learning. Such a real and convenient learning environment can enable students to communicate with successful entrepreneurs in real time, which makes students' entrepreneurial psychological capital play a greater role. Therefore, this study puts forward the following hypothesis:

H5: XR technology plays an intermediary role in the positive promotion of students' entrepreneurial exploratory learning.

According to the abovementioned literature summary, the research model of this study is proposed, as shown in Figure 1.

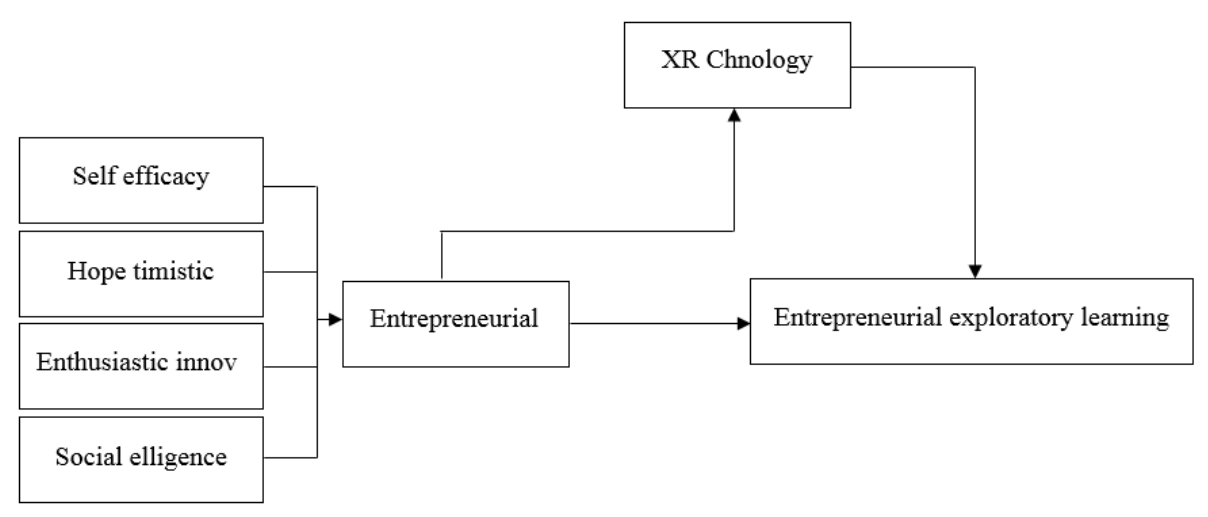

Fig. 1. Research model 


\section{$3 \quad$ Research design}

\subsection{Measuring tool}

The scale design of this study consists of three parts, with 30 topics. The first part is the respondents' basic information, including subject ( a value of 1 for liberal arts, a value of 2 for science, and a value of 3 for engineering), grade (a value of 1 for grade 1 , a value of 2 for grade 2 , a value of 3 for grade 3 , and a value of 4 for grade 4 ), gender (a value of 1 for girls and a value of 2 for boys), and whether they have XR experience (a value of 0 for no and a value of 1 for yes). The second part covers four factors of entrepreneurial psychological capital. This study adopts Luthans, F (2004)'s psychological capital scale, which includes four aspects: self-efficacy, hope and optimism, enthusiasm for innovation, and social intelligence. This study selects representative topics, with 18 items. A large number of research documents have proven that this questionnaire has good reliability and validity and has been widely recognized by domestic scholars. The third part adopts the exploratory questionnaire of exploratory learning of Atuahene-Gima, K (2007), including five questions and the application of XR technology [4], including three questions. The two scales used in this study are from the more mature scales in the literature at home and abroad. Thus, the scoring method adopts Likert's five-point scoring method, and the degree of compliance is divided into five levels, namely, very inconsistent, relatively inconsistent, general, very consistent, and relatively consistent, with the corresponding score of 1 to 5 .

\subsection{Research objects}

Considering the large-scale development of the information technology industry in China, this industry is a new industry in China, which has a good market prospect and attracts a large number of college graduates to start businesses. Therefore, this study adopts the method of random sampling in the university campus, presents the QR code generated by the questionnaire made on the Questionnaire Platform (www.wjx.cn) in advance on the spot, and conducts a survey on the freshmen to seniors by scanning the QR code on the mobile phone of the students on the spot. The students directly fill in the questionnaire online on the Questionnaire Platform. The questionnaire was distributed for 2 days. A total of 145 questionnaires were finally recovered, and 109 valid questionnaires were finally formed, with an effective rate of $75.17 \%$. The basic information and descriptive statistical results of specific respondents are shown in Table 1.

Table 1. Frequency analysis results

\begin{tabular}{|c|c|c|c|c|}
\hline Name & Option tag & Frequency & Percentage (\%) & Cumulative percentage (\%) \\
\hline \multirow{3}{*}{ Subject } & Liberal arts & 26 & 23.85 & 23.85 \\
\cline { 2 - 5 } & Science & 36 & 33.03 & 56.88 \\
\cline { 2 - 5 } & Field of engineering & 47 & 43.12 & 100 \\
\hline \multirow{2}{*}{ Grade } & Grade One & 20 & 18.35 & 18.35 \\
\cline { 2 - 5 } & Grade Two & 32 & 29.36 & 47.71 \\
\hline
\end{tabular}




\begin{tabular}{|l|c|c|c|c|}
\hline \multirow{2}{*}{ Gender } & Grade Three & 31 & 28.44 & 76.15 \\
\cline { 2 - 5 } & Grade Four & 26 & 23.85 & 100 \\
\cline { 2 - 5 } & Woman & 20 & 18.35 & 18.35 \\
\hline \begin{tabular}{l} 
XR $\begin{array}{l}\text { Experience } \\
\text { in use }\end{array}$ \\
\cline { 2 - 5 }
\end{tabular} & Man & 89 & 81.65 & 32.11 \\
\hline
\end{tabular}

\section{$4 \quad$ Result analysis}

\subsection{Reliability and validity test}

The collected data need to be quantitatively analyzed to verify the relationship between students' entrepreneurial psychological capital and students' entrepreneurial exploratory learning. In this study, the data are statistically processed by reliability and validity test and path analysis.

First, the reliability test of the scale verifies the consistency and stability of the results measured by the scale. The greater the reliability of the measurement is greater and the internal consistency of the scale is better when the reliability value of the scale is higher. In statistical analysis, Cronbach's $\alpha$ value is generally used to evaluate the reliability level of data. The internal consistency of data is higher and the reliability of results is stronger when Cronbach's $\alpha$ is higher.

As shown in Table 2, Cronbach's $\alpha$ coefficient is 0.844 on the whole, and the coefficients of $0.872,0.886,0.856,0.837,0.777$, and 0.834 of six variables are all greater than 0.7 . Therefore, the questionnaire is stable and reliable and has good internal consistency. Thus, it can be accepted and adopted.

Table 2. Reliability test results

\begin{tabular}{|c|c|c|c|c|c|}
\hline Variable & $\begin{array}{l}\text { Question } \\
\text { number }\end{array}$ & $\begin{array}{l}\text { Total correlation of cor- } \\
\text { rection items (CITC) }\end{array}$ & $\begin{array}{c}\text { Item deleted } \alpha \\
\text { coefficient }\end{array}$ & $\begin{array}{c}\text { Cronbach } \alpha \\
\text { coefficient }\end{array}$ & $\begin{array}{c}\text { Cronbach } \alpha \\
\text { coefficient }\end{array}$ \\
\hline \multirow{5}{*}{$\begin{array}{l}\text { Self efficacy } \\
\text { (Factor1) }\end{array}$} & A1 & 0.650 & 0.856 & \multirow{5}{*}{0.872} & \multirow{14}{*}{0.844} \\
\hline & A2 & 0.638 & 0.861 & & \\
\hline & $\mathrm{A} 3$ & 0.773 & 0.826 & & \\
\hline & $\mathrm{A} 4$ & 0.739 & 0.835 & & \\
\hline & A5 & 0.699 & 0.844 & & \\
\hline \multirow{3}{*}{$\begin{array}{l}\text { Hope } \\
\text { optimistic } \\
\text { (Factor2) }\end{array}$} & B1 & 0.769 & 0.846 & \multirow{3}{*}{0.886} & \\
\hline & B2 & 0.809 & 0.810 & & \\
\hline & B3 & 0.757 & 0.856 & & \\
\hline \multirow{4}{*}{$\begin{array}{l}\text { Enthusiastic } \\
\text { innovation } \\
\text { (Factor3) }\end{array}$} & $\mathrm{C} 1$ & 0.732 & 0.803 & \multirow{4}{*}{0.856} & \\
\hline & $\mathrm{C} 2$ & 0.676 & 0.834 & & \\
\hline & $\mathrm{C} 3$ & 0.695 & 0.818 & & \\
\hline & $\mathrm{C} 4$ & 0.724 & 0.806 & & \\
\hline \multirow{2}{*}{$\begin{array}{l}\text { Social } \\
\text { intelligence }\end{array}$} & D1 & 0.558 & 0.821 & \multirow{2}{*}{0.837} & \\
\hline & D2 & 0.678 & 0.796 & & \\
\hline
\end{tabular}




\begin{tabular}{|c|c|c|c|c|}
\hline (Factor4) & D3 & 0.754 & 0.781 & \\
\hline & D4 & 0.631 & 0.808 & \\
\hline & D5 & 0.516 & 0.829 & \\
\hline & D6 & 0.550 & 0.824 & \\
\hline & E1 & 0.570 & 0.730 & \\
\hline Exploratory & E2 & 0.520 & 0.748 & \\
\hline learning & E3 & 0.597 & 0.720 & 0.777 \\
\hline (Factor5) & E4 & 0.517 & 0.748 & \\
\hline & E5 & 0.556 & 0.735 & \\
\hline XR & $\mathrm{F} 1$ & 0.757 & 0.707 & \\
\hline Technology & F2 & 0.753 & 0.712 & 0.834 \\
\hline (Factor6) & F3 & 0.591 & 0.864 & \\
\hline
\end{tabular}

Validity analysis examines the accuracy of the measurement indicators of the scale. Constructive validity is the most rigorous method to test the validity of a questionnaire. It refers to the extent to which the scale can measure the theoretical construction or psychological characteristics. Given that the scale used in this study is a mature scale which has been tested many times by scholars at home and abroad and has good content validity in essence, this part will test the construct validity and discrimination validity of variables and questionnaires.

KMO and Bartlett's sphericity test are the methods to measure the validity of the questionnaire. The results in Table 3 show that the overall KMO value of the questionnaire is 0.787 . The significance of Bartlett's sphericity test is 0.000 , which is less than 0.01 . Therefore, the data of the scale are correlated, and the questionnaire has good validity.

Table 3. KMO and Bartlett's inspection

\begin{tabular}{|c|c|c|}
\hline \multicolumn{2}{|l|}{ Kmo value } & 0.787 \\
\hline \multirow{3}{*}{ Bartlett Sphericity Test } & Approximate chi square & 1517.834 \\
\hline & df & 325 \\
\hline & $\mathrm{P}$ value & 0 \\
\hline
\end{tabular}

Tables 4 and 5 show that AVE is greater than 0.5 and CR value is greater than 0.7 , which means that aggregation validity is high. The discrimination validity is analyzed. For factors 1-6, the square root value of AVE is larger than the maximum value of absolute value of correlation coefficient between factors, which indicates that the overall discrimination validity of the questionnaire is good. 
Paper - Influence of Students' Entrepreneurial Psychological Capital on Entrepreneurial Exploratory..

Table 4. AVE and CR index results of the model

\begin{tabular}{|l|c|c|}
\hline \multicolumn{1}{|c|}{ Factor } & Mean variance extraction ave value & Combined reliability CR value \\
\hline Factor1 & 0.582 & 0.874 \\
\hline Factor2 & 0.725 & 0.888 \\
\hline Factor3 & 0.615 & 0.862 \\
\hline Factor4 & 0.474 & 0.838 \\
\hline Factor5 & 0.407 & 0.774 \\
\hline Factor6 & 0.665 & 0.851 \\
\hline
\end{tabular}

Table 5. Distinguishing validity: Pearson correlation and square root value of AVE

\begin{tabular}{|l|c|c|c|c|c|c|}
\hline & Factor1 & Factor2 & Factor3 & Factor4 & Factor5 & Factor6 \\
\hline Factor1 & 0.763 & - & - & - & - & - \\
\hline Factor2 & 0.498 & 0.852 & - & - & - & - \\
\hline Factor3 & 0.593 & 0.614 & 0.784 & - & - & - \\
\hline Factor4 & 0.093 & 0.169 & 0.155 & 0.688 & - & - \\
\hline Factor5 & -0.001 & 0.015 & 0.029 & 0.011 & 0.638 & - \\
\hline Factor6 & -0.03 & -0.024 & 0.029 & 0.033 & 0.631 & 0.815 \\
\hline
\end{tabular}

The following results are obtained from Table 6.

Suppose H1 holds. Specifically, self-efficacy significantly positively impacts entrepreneurial exploratory learning. Self-efficacy plays a key role as the main factor to promote students' choice of exploratory learning. Self-efficacy includes self-belief and the ability to deal with multiple tasks, which makes students have psychological prerequisites for exploratory learning. In particular, the adoption of entrepreneurial exploratory learning in schools can enable students to further improve their sense of self-efficacy, cultivate them to think about the difficulties and challenges in the entrepreneurial process from a more macro and long-term perspective, understand the hardships in the entrepreneurial process, face and deal with all kinds of setbacks in entrepreneurship more calmly, solve entrepreneurial risks more actively, and improve the exploratory learning achievement of entrepreneurial knowledge.

Suppose $\mathrm{H} 2$ holds. Hope significantly positively impacts entrepreneurial exploratory learning. Students with high entrepreneurial psychological capital generally show higher hope and optimism. When students encounter setbacks in the process of entrepreneurship, they can better adjust their state, use all kinds of resources and interpersonal relationships around them to help them tide over difficulties, and choose exploratory learning methods that are more in line with market demand to experience the hardships of entrepreneurship. People with high psychological capital have good expectations and cognition of various possible situations in the process of entrepreneurship. They will attribute positive events to their own and lasting reasons rather than external, random, and uncontrollable reasons. Therefore, they hope that optimistic students will hold a very positive attitude toward entrepreneurial exploratory learning, It can also make them hold a more positive view of the entrepreneurial process and have a higher entrepreneurial possibility. 
Suppose H3 holds. In particular, enthusiasm significantly positively impacts entrepreneurial exploratory learning. The main ages of students are between 18 and 26 years old, and they are in the golden age period with vigorous energy and full of various imaginations for the future. By improving their enthusiasm and innovation characteristics, they can choose entrepreneurial exploratory learning more, promote them to maintain a positive and positive attitude toward entrepreneurial exploratory learning, and make them have stronger entrepreneurial ability by simulating various role experiences in the process of learning entrepreneurship. The possibility that they still maintain a warm entrepreneurial attitude in the face of entrepreneurial difficulties can be comprehensively improved.

Suppose H4 is not true. Specifically, social intelligence has no significant positive impact on entrepreneurial exploratory learning. This conclusion is not quite consistent with the conclusions of considerable previous literature, and the main reason may be that the object of this study is male engineering students, and some may lack understanding of social intelligence. This conclusion is not true, and a further and deeper reason may exist, which is that students mainly live in the university campus every day, and their daily contact objects are classmates and teachers, and they do not have a perceptual understanding of the entrepreneurial market. The lack of social intelligence leads to their insufficient understanding of the importance of entrepreneurial exploratory learning, and they have not experienced the benefits of social interaction activities and more enterprise personnel learning other people's experiences in social interaction. It also inspires universities to further increase the number of social people with real business entrepreneurial experience to explain to the school. Thus, students can more obtain the real entrepreneurial exploratory learning process, and they can abandon the traditional entrepreneurial theory teaching mode by counselors without entrepreneurial experience.

Table 6. Regression analysis results

\begin{tabular}{|c|c|c|c|c|c|c|c|}
\hline $\mathbf{X}$ & $\rightarrow$ & $\mathbf{Y}$ & $\begin{array}{c}\text { Non standardized } \\
\text { regression coefficient }\end{array}$ & $\mathbf{S E}$ & $\mathbf{Z}$ (CR value) & $\mathbf{P}$ & $\begin{array}{c}\text { Standardized regression } \\
\text { coefficient }\end{array}$ \\
\hline Factor1 & $\rightarrow$ & Factor5 & 0.220 & 0.101 & 2.174 & 0.030 & 0.258 \\
\hline Factor2 & $\rightarrow$ & Factor5 & 0.483 & 0.144 & 3.345 & 0.001 & 0.530 \\
\hline Factor3 & $\rightarrow$ & Factor5 & 0.304 & 0.095 & 3.205 & 0.001 & 0.358 \\
\hline Factor4 & $\rightarrow$ & Factor5 & -0.154 & 0.113 & -1.365 & 0.172 & -0.168 \\
\hline
\end{tabular}

H5 is assumed to be true in Tables 7 and 8. XR technology plays a completely mediating role in the positive promotion of students' entrepreneurial exploratory learning by the students' entrepreneurial psychological capital society. In fact, XR technology does not exist in isolation. It can be integrated with cutting-edge technologies such as big data, 5G communication technology, and AI, which can create a more effective exploratory learning environment for students and improve the learning effect of immersive experience. In particular, XR technology combined with big data technology can batch process and scientifically analyze the more complex and nonlinear learning record data in the process of entrepreneurial exploratory learning, create a more real 
Paper - Influence of Students' Entrepreneurial Psychological Capital on Entrepreneurial Exploratory..

scene for students, and provide decision-making reference for students' entrepreneurship.

Table 7. Intermediary effect model test

\begin{tabular}{|c|c|c|c|}
\hline & Exploratory learning & XR Technology & Exploratory learning \\
\hline Constant & $2.699^{* * *}(9.134)$ & $2.566^{* *}(10.714)$ & $1.136^{* *}(3.056)$ \\
\hline $\begin{array}{l}\text { Entrepreneurial psychological } \\
\text { capital }\end{array}$ & $0.281^{* *}(3.444)$ & $0.340^{* *}(5.143)$ & $0.074(0.927)$ \\
\hline XR Technology & & & $0.609^{* *}(5.845)$ \\
\hline Sample size & 109 & 109 & 109 \\
\hline $\mathrm{R}^{2}$ & 0.1 & 0.198 & 0.319 \\
\hline Adjust $\mathrm{R}^{2}$ & 0.091 & 0.191 & 0.306 \\
\hline F value & $\begin{array}{c}\mathrm{F} \\
(1,107)=11.858, \mathrm{p}=0.00 \\
1\end{array}$ & $\begin{array}{c}\mathrm{F} \\
(1,107)=26.450, \mathrm{p}=0.00 \\
0\end{array}$ & $\begin{array}{c}\mathrm{F} \\
(2,106)=24.851, \mathrm{p}=0.00 \\
0\end{array}$ \\
\hline
\end{tabular}

${ }^{*} \mathrm{P}<0.05^{* *} \mathrm{P}<0.01$ the value of $\mathrm{T}$ in brackets

Table 8. Intermediary test results

\begin{tabular}{|c|c|c|c|c|c|c|c|c|c|c|}
\hline Item & $\begin{array}{l}\mathrm{C} \text { total } \\
\text { effect }\end{array}$ & A & B & $\begin{array}{l}a^{*} b \text { inter- } \\
\text { mediary ef- } \\
\text { fect value }\end{array}$ & \begin{tabular}{|c|}
$\mathbf{a}^{*} \mathbf{b}$ \\
$($ Boot \\
SE)
\end{tabular} & $\begin{array}{l}\mathbf{a}^{*} \mathbf{b}(\mathrm{z} \\
\text { value })\end{array}$ & $\begin{array}{l}\mathbf{a}^{*} \mathbf{b}(\mathbf{p} \\
\text { value })\end{array}$ & $\begin{array}{c}a^{*} \mathbf{b} \\
(95 \% \\
\text { BootCI) }\end{array}$ & $\begin{array}{l}\text { c' di- } \\
\text { rect } \\
\text { effect }\end{array}$ & \begin{tabular}{|c|} 
Test \\
conclu- \\
sion
\end{tabular} \\
\hline $\begin{array}{l}\text { Entrepreneurial } \\
\text { psychological } \\
\text { capital => XR } \\
\text { technology => } \\
\text { exploratory } \\
\text { learning }\end{array}$ & $0.281^{* *}$ & $0.340^{* *}$ & $0.609^{* *}$ & 0.207 & 0.008 & 26.785 & 0 & $\begin{array}{c}0.084 \sim \\
0.401\end{array}$ & 0.074 & $\begin{array}{c}\text { Com- } \\
\text { plete } \\
\text { media- } \\
\text { tion }\end{array}$ \\
\hline
\end{tabular}

Table 9 shows that no significant difference exists between different genders for exploratory learning, and XR use experience shows a significant difference for exploratory learning. Students' experience and use of XR technology has a very important impact on whether they adopt entrepreneurial exploratory learning and the effectiveness of exploratory learning. The popularity of XR technology experience perception among students can be enhanced by enlightening universities, as the main responsible units of entrepreneurship education, and introducing XR technology. This way enables students to obtain more educational methods with rich entrepreneurial experience.

Table 9. Difference t-test of gender and XR use experience on exploratory learning

\begin{tabular}{|c|c|c|c|c|}
\hline \multirow{6}{*}{ Exploratory learning } & \multicolumn{2}{|c|}{ Gender (mean standard deviation) } & \multirow{2}{*}{$\mathrm{T}$} & \multirow{2}{*}{$\mathrm{P}$} \\
\hline & $1(\mathrm{n}=20)$ & $2(\mathrm{n}=89)$ & & \\
\hline & $3.93 \pm 0.52$ & $3.65 \pm 0.66$ & 1.769 & 0.08 \\
\hline & \multicolumn{2}{|c|}{$X R$ experience (mean SD) } & $\mathrm{T}$ & $P$ \\
\hline & $0(\mathrm{n}=35)$ & $1(\mathrm{n}=74)$ & 1 & \\
\hline & $3.56 \pm 0.67$ & $4.00 \pm 0.47$ & -3.485 & $0.001 * *$ \\
\hline
\end{tabular}


Paper-Influence of Students' Entrepreneurial Psychological Capital on Entrepreneurial Exploratory...

\section{Conclusion}

XR technology makes the original entrepreneurial knowledge learning in the given time and space dimension more colorful, which enables students to learn entrepreneurial knowledge across time and space by means of exploratory learning, improves the entrepreneurial knowledge experience beyond reality, and further enhances the entrepreneurial willingness level and entrepreneurial effectiveness of students. On the basis of emotional and social cognitive theories, this study puts forward a research model of students' entrepreneurial psychological capital on entrepreneurial exploratory learning. Whether XR plays a mediating role in promoting entrepreneurial exploratory learning is also verified. The results show that Cronbach's $\alpha$ coefficient is 0.844 , the KMO value is 0.787 , and the corresponding $\mathrm{p}$ value is 0 , which reflects that the designed questionnaire has good reliability and validity. The self-efficacy, hope and optimism, and enthusiasm and innovation of students' entrepreneurial psychological capital significantly positively impact students' entrepreneurial exploratory learning. XR technology plays a complete intermediary effect in the positive promotion of students' entrepreneurial exploratory learning by students' entrepreneurial psychological capital society. XR use experience shows significant differences in exploratory learning. Comprehensively expanding the constituent factors of entrepreneurial psychological capital, analyzing the impact of XR technology on students' entrepreneurial performance, and constructing entrepreneurial knowledge situational learning environment created by XR technology are future research directions.

\section{References}

[1] Bandura A. Human agency in social Cognitive theory. American Psychologist, 1989, (44), pp. 1175- 1184. https://doi.org/10.1037/0003-066X.44.9.1175

[2] Lazarus Richard S. On the primacy of Cognition. American Psychologist, 1984, vol. 39(2), pp. 124-129. https://doi.org/10.1037/0003-066X.39.2.124

[3] Luthans, F., Luthans, K. W., \& Luthans, B. C. Positive psychological capital: Beyond human and social capital. Business Horizons, 2004, vol. 47(1), pp. 45-50. https://doi.org/10. 1016/j.bushor.2003.11.007

[4] Atuahene-Gima, K., \& Murray, J. Y. Exploratory and exploitative learning in new product development: A social capital perspective on new technology ventures in China. Journal of International Marketing, 2017, vol. 15(2), pp. 1-29. https://doi.org/10.1509/jimk.15.2.1

[5] Power, J., Lynch, R., \& McGarr, O. Difficulty and self-efficacy: An exploratory study. British Journal of Educational Technology, 2020, vol. 51(1), pp. 281-296. https://doi.org/ 10.1111/bjet.12755

[6] Shen, D., Cho, M. H., Tsai, C. L., \& Marra, R. Unpacking online learning experiences: Online learning self-efficacy and learning satisfaction. The Internet and Higher Education, 2013, 19, pp. 10-17. https://doi.org/10.1016/j.iheduc.2013.04.001

[7] Choi, N., Fuqua, D. R., \& Griffin, B. W. Exploratory analysis of the structure of scores from the multidimensional scales of perceived self-efficacy. Educational and psychological measurement, 2001, vol. 61(3), pp. 475-489. https://doi.org/10.1177/00131640121971338 
Paper - Influence of Students' Entrepreneurial Psychological Capital on Entrepreneurial Exploratory...

[8] Ruys, I., Van Keer, H., \& Aelterman, A. Collaborative learning in pre-service teacher education: an exploratory study on related conceptions, self-efficacy and implementation. Educational Studies, 2010, vol. 36(5), pp. 537-553. https://doi.org/10.1080/03055691003 $\underline{729021}$

[9] Greiman, B. C., \& Addington, L. S. Youth leadership development self-efficacy: An exploratory study involving a new construct. Journal of Leadership Education, 2008, vol. 7(1), pp. 1-23. https://doi.org/10.12806/V7/I1/RF1

[10] Chiaburu, D. S., \& Marinova, S. V. What predicts skill transfer? An exploratory study of goal orientation, training self-efficacy and organizational supports. International journal of training and development, 2005, vol. 9(2), pp. 110-123. https://doi.org/10.1111/j.14682419.2005.00225.x

[11] Zheng, J., Li, S., \& Zheng, Y. Students' technology acceptance, motivation and self-efficacy towards the eSchoolbag: an exploratory study. Int. J. Infonomics, 2017, vol. 10(3), pp. 13501358. https://doi.org/10.20533/iji.1742.4712.2017.0165

[12] Stankevicius, A., Huys, Q. J., Kalra, A., \& Seriès, P. Optimism as a prior belief about the probability of future reward. PLoS computational biology, 2014, vol. 10(5), pp. e1003605. https://doi.org/10.1371/journal.pcbi.1003605

[13] Hoy, W. K., Tarter, C. J., \& Hoy, A. W. Academic optimism of schools: A force for student achievement. American educational research journal, 2006, vol. 43(3), pp. 425-446. https://doi.org/10.3102/00028312043003425

[14] Kulophas, D., \& Hallinger, P. Leadership that matters: creating cultures of academic optimism that support teacher learning in Thailand. Journal of educational administration, 2020, vol. 58(6), pp.605-627. https://doi.org/10.1108/JEA-12-2019-0222

[15] Hamm, J. M., Perry, R. P., Chipperfield, J. G., Parker, P. C., \& Heckhausen, J. A motivation treatment to enhance goal engagement in online learning environments: Assisting failureprone college students with low optimism. Motivation Science, 2019, vol. 5(2), pp. 116. https://doi.org/10.1037/mot0000107

[16] Di Paolantonio, M. The Cruel Optimism of Education and Education's Implication with 'Passing-on'. Journal of Philosophy of Education, 2016, vol. 50(2), pp. 147-159. https://doi. org/10.1111/1467-9752.12197

[17] Rose, E Cause for optimism: Engaging in a vital conversation about online learning. Foundations of Science, 2017, vol. 22(2), pp. 373-376. https://doi.org/10.1007/s10699-015$\underline{9445-8}$

[18] Slick, S. Teachers are enthusiastic participants in a learning community. The Clearing House, 2002, vol. 75(4), pp. 198-201. https://doi.org/10.1080/00098650209604931

[19] DeRobertis, E. M. Becoming enthusiastic about learning for the first time as a child. Journal of Humanistic Psychology, 2016, vol. 56(4), pp. 394-413. https://doi.org/10.1177/ $\underline{0022167815574430}$

[20] Serin, H. The role of passion in learning and teaching. International Journal of Social Sciences \& Educational Studies, 2017, vol. 4(1), pp. 60-64. https://doi.org/10.23918/ijsses.v4i1p60

[21] Noble, K. D., \& Childers, S. A. A passion for learning: The theory and practice of optima match at the University of Washington. Journal of Advanced Academics, 2008, vol. 19(2), pp. 236-270. https://doi.org/10.4219/jaa-2008-774

[22] Horng, J. S., Liu, C. H., Chou, S. F., \& Huang, Y. C. The roles of university education in promoting students' passion for learning, knowledge management and entrepreneurialism. Journal of Hospitality and Tourism Management, 2020, 44, pp. 162-170. https://doi.org/ $\underline{10.1016 / j . j h t m .2020 .06 .005}$ 
Paper - Influence of Students' Entrepreneurial Psychological Capital on Entrepreneurial Exploratory...

[23] Kutnowski, M. This is why we teach: Igniting a passion for learning in linked courses. About Campus, 2005, vol. 10(1), pp. 23-26. https://doi.org/10.1002/abc. 120

[24] Wang, Y. F., \& Teng, C. C. A transformative sustainability learning model for inculcating passion for learning about green food and beverage in hospitality college students. Journal of Teaching in Travel \& Tourism, 2019, vol. 19(4), pp. 302-325. https://doi.org/10.1080/ 15313220.2019 .1592060

[25] Suliman, W. A. The relationship between learning styles, emotional social intelligence, and academic success of undergraduate nursing students. Journal of Nursing Research, 2010, vol. 18(2), pp. 136-143. https://doi.org/10.1097/JNR.0b013e3181dda797

[26] Kaukiainen, A., Salmivalli, C., Lagerspetz, K., Tamminen, M., Vauras, M., Mäki, H., \& Poskiparta, E. Learning difficulties, social intelligence, and self-concept: Connections to bully-victim problems. Scandinavian journal of psychology, 2002, vol. 43(3), pp. 269-278. https://doi.org/10.1111/1467-9450.00295

[27] Arghode, V. Emotional and social intelligence competence: Implications for instruction. International Journal of Pedagogies and Learning, 2013, vol. 8(2), pp. 66-77. https://doi.org/ 10.5172/ijpl.2013.8.2.66

[28] Seal, C. R., Boyatzis, R. E., \& Bailey, J. R. Fostering emotional and social intelligence in organizations. Organization Management Journal, 2006, vol. 3(3), pp. 190-209. https://doi. org/10.1057/omj.2006.19

[29] Hong, E. A qualitative analysis of social intelligence in nonprofit organizations: external knowledge acquisition for human capital development, organizational learning and innovation. Knowledge Management Research \& Practice, 2015, vol. 13(4), pp. 463-474. https://doi.org/10.1057/kmrp.2013.63

[30] Meyer, K. A., \& Jones, S. J. Do Students Experience" Social Intelligence," Laughter, and Other Emotions Online? Journal of asynchronous learning networks, 2012, vol. 16(4), pp. 99-111. https://doi.org/10.24059/olj.v16i4.283

[31] Kang, J., Diederich, M., Lindgren, R., \& Junokas, M. Gesture patterns and learning in an embodied XR science simulation. Educational Technology \& Society, 2021, vol. 24(2), pp. 77-92.

[32] Nisiotis, L., \& Alboul, L. Work-In-Progress-An Intelligent Immersive Learning System Using AI, XR and Robots. In 2021 7th International Conference of the Immersive Learning Research Network IEEE, 2021, pp. 1-3. https://doi.org/10.23919/iLRN52045.2021.9459358

[33] Ioannou, A., Bhagat, K. K., \& Johnson-Glenberg, M. C. Guest Editorial: Learning Experience Design: Embodiment, Gesture, and Interactivity in XR. Journal of Educational Technology \& Society, 2021, vol. 24(2), pp.73-76.

[34] Young, A., \& Manson, R. Pre-Conference Workshop-Creating XR Experiences for the Classroom. In 2018 IEEE International Conference on Teaching, Assessment, and Learning for Engineering IEEE, 2018, pp.1217-1218. https://doi.org/10.1109/TALE.2018.8615379

\section{$7 \quad$ Author}

Zhe Liu is a Lecturer in College of Culture and education, Henan Economy and Trade Vocational College, Zhengzhou, 450002, China.

Article submitted 2021-11-01. Resubmitted 2021-12-04. Final acceptance 2021-12-06. Final version published as submitted by the author. 